\title{
Biosynthesis, mode of action, and functional significance of neurosteroids in the Purkinje cell
}

\section{Kazuyoshi Tsutsui *, Kazuyoshi Ukena, Hirotaka Sakamoto, Shin-Ichiro Okuyama and Shogo Haraguchi}

Laboratory of Integrative Brain Sciences, Department of Biology, Waseda University, and Center for Medical Life Science of Waseda University, Shinjuku-ku, Tokyo, Japan

\section{Edited by:}

Hubert Vaudry, University of Rouen,

France

Reviewed by:

Mitsuhiro Kawata, Kyoto Prefectural University of Medicine, Japan

Michael Schumacher, INSERM,

France

\section{*Correspondence:}

Kazuyoshi Tsutsui, Laboratory of

Integrative Brain Sciences,

Department of Biology, Waseda

University, and Center for Medical

Life Science of Waseda University,

2-2 Wakamatsu-cho, Shinjuku-ku,

Tokyo 162-8480, Japan.

e-mail:k-tsutsui@waseda.jp
The brain has traditionally been considered to be a target site of peripheral steroid hormones. In addition to this classical concept, we now know that the brain has the capacity to synthesize steroids de novo from cholesterol, the so-called "neurosteroids." In the middle 1990s, the Purkinje cell, an important cerebellar neuron, was identified as a major site for neurosteroid formation in the brain of mammals and other vertebrates. This discovery has provided the opportunity to understand neuronal neurosteroidogenesis in the brain. In addition, biological actions of neurosteroids are becoming clear by the studies using the Purkinje cell, an excellent cellular model, which is known to play an important role in memory and learning processes. Based on the studies on mammals over the past decade, it is considered that the Purkinje cell actively synthesizes progesterone and estradiol from cholesterol during neonatal life, when cerebellar neuronal circuit formation occurs. Both progesterone and estradiol promote dendritic growth, spinogenesis, and synaptogenesis via each cognate nuclear receptor in the developing Purkinje cell. Such neurosteroid actions mediated by neurotrophic factors may contribute to the formation of cerebellar neuronal circuit during neonatal life. $3 \alpha, 5 \alpha$-Tetrahydroprogesterone (allopregnanolone), a progesterone metabolite, is also synthesized in the cerebellum and considered to act as a survival factor of Purkinje cells in the neonate. This review summarizes the current knowledge regarding the biosynthesis, mode of action, and functional significance of neurosteroids in the Purkinje cell during development in terms of synaptic formation of cerebellar neuronal networks.

Keywords: neurosteroids, progesterone, estradiol, allopregnanolone, dendritic growth, synaptogenesis, neuronal circuit, Purkinje cell

\section{INTRODUCTION}

The cerebellar cortex forms relatively simple neuronal networks compared to those of other brain regions. Therefore, the cerebellar cortex has been used as an excellent model system to study synaptic formation of neural networks in vertebrates, in particular mammals. It is well known that marked morphological changes occur in the cerebellum after birth during neonatal life and the formation of the cerebellar cortex completes in the neonate through the processes of migration of external granule cells, neuronal and glial growth, and synaptogenesis in the rat (Altman, 1972a,b). It is important to understand the mechanism underlying synaptic formation of cerebellar neuronal networks during development in mammals and other vertebrates.

In the middle 1990s, Tsutsui and colleagues discovered that the Purkinje cell, an important cerebellar neuron, is a major site for neurosteroid formation in a variety of vertebrates including mammals (Tsutsui and Yamazaki, 1995; Usui et al., 1995; Ukena et al., 1998, 1999; Takase et al., 1999; Matsunaga et al., 2001; Sakamoto et al., 2001a, 2003a; Agís-Balboa et al., 2006, 2007). This was the first observation of neuronal neurosteroidogenesis in the brain. This discovery has provided the opportunity to understand neuronal neurosteroidogenesis in the brain. Furthermore, the Purkinje cell has served as an excellent cellular model for the study of biological actions of neurosteroids and provided new insights into the mechanisms underlying the formation of cerebellar neuronal networks during development.

Here we summarize the biosynthesis and biological actions of neurosteroids in the Purkinje cell during development in terms of synaptic formation of cerebellar neuronal networks. We also describe what are currently known about the mode of action and the functional significance of neurosteroids produced in the Purkinje cell.

\section{OVERVIEW OF PURKINJE CELLS AS A MAJOR SITE FOR NEUROSTEROIDOGENESIS}

The identification of neurosteroidogenic cells is essential to analyze neurosteroid actions in brain function. It is also necessary to know which neurosteroids are synthesized in specific brain regions at specific period during development. Such information enables us to develop hypotheses predicting the potential roles of those neurosteroids in the brain. Thus, the studies for this exciting area in "neuroendocrine science" should be focused on the biosynthesis and biological actions of neurosteroids produced locally in the identified neurosteroidogenic cells underlying important brain functions.

The oligodendrocyte was first accepted to be the primary site for neurosteroid formation in the brain (for reviews, see Baulieu, 1997; Compagnone and Mellon, 2000). Subsequently, astrocytes 
and some neurons were shown to express some steroidogenic enzymes (Mellon and Deschepper, 1993). Thus, glial cells were generally accepted to be the site for neurosteroid formation. However, whether neurons located in the brain produce neurosteroids was unknown in vertebrates until the middle 1990s. Tsutsui and colleagues discovered that the Purkinje cell is a major site for neurosteroid formation in birds and subsequently in other vertebrates including mammals (Tsutsui and Yamazaki, 1995; Usui et al., 1995; Ukena et al., 1998, 1999; Takase et al., 1999; Matsunaga et al., 2001; Sakamoto et al., 2001a, 2003a; Agís-Balboa et al., 2006, 2007). From the past 10 years of research on mammals, the colocalization of several kinds of steroidogenic enzymes in the Purkinje cell has been demonstrated.
In mammals, the Purkinje cell possesses several kinds of steroidogenic enzymes, such as cytochrome P450 side-chain cleavage (P450scc) enzyme and $3 \beta$-hydroxysteroid dehydrogenase $/ \Delta^{5}$ $\Delta^{4}$-isomerase ( $3 \beta$-HSD), and actively produces progesterone during neonatal life (Furukawa et al., 1998; Ukena et al., 1998, 1999; Figure 1). $3 \alpha, 5 \alpha$-Tetrahydroprogesterone (allopregnanolone), a progesterone metabolite, is also synthesized in the neonatal cerebellum (Tsutsui and Ukena, 1999; Tsutsui et al., 2003b,c, 2004; Agís-Balboa et al., 2006, 2007; Figure 1). Subsequently, biological actions of progesterone (Sakamoto et al., 2001b, 2002, 2003b; Ghoumari et al., 2003) and the progesterone metabolite allopregnanolone (Griffin et al., 2004) are becoming clear by the studies on mammals using the Purkinje cell which is known to play an

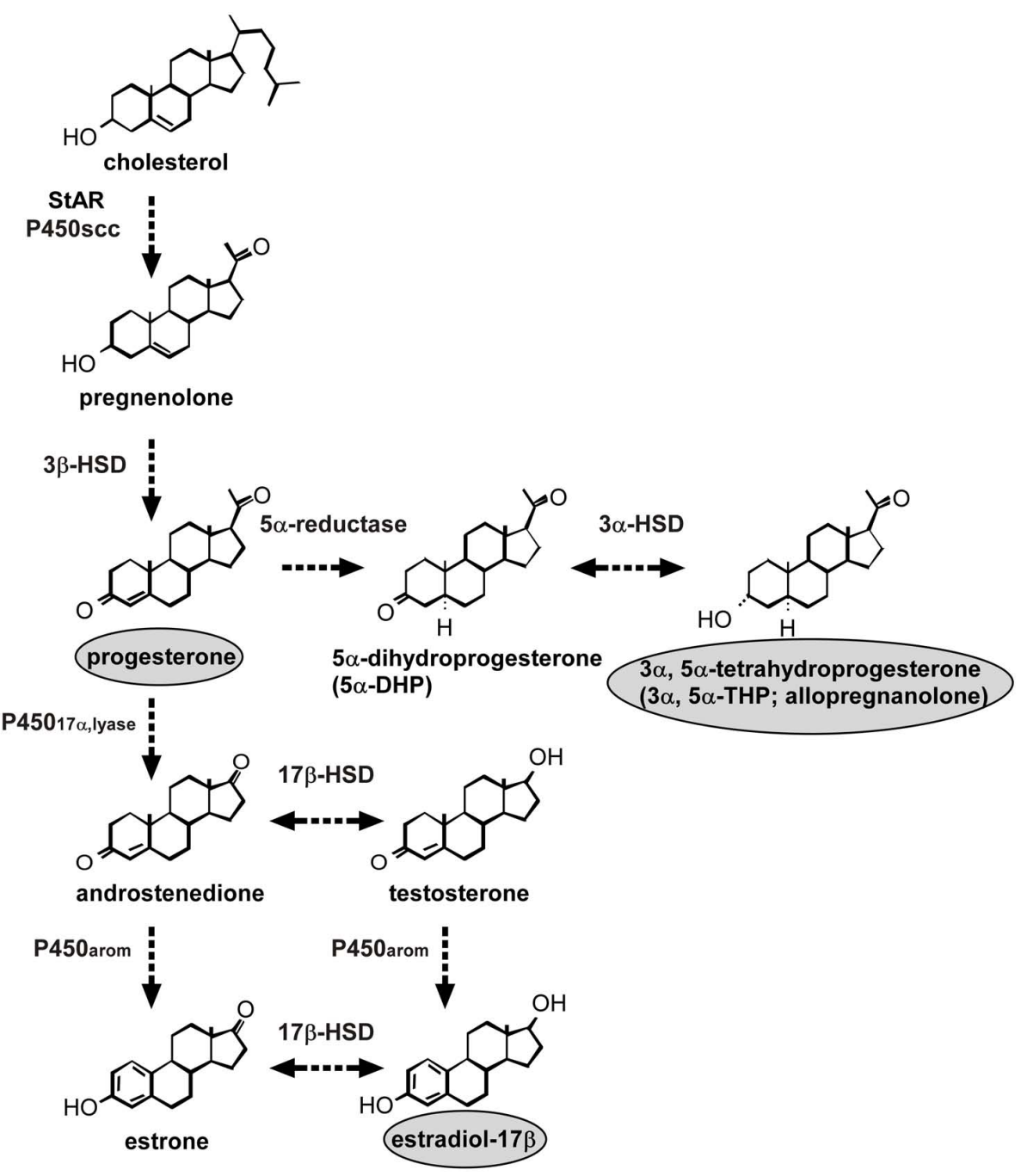

FIGURE 1 | Neurosteroid formation in the Purkinje cell during development. The Purkinje cell possesses several kinds of steroidogenic enzymes. The expression of P450scc remains during neonatal development and in adulthood, indicating the constant production of pregnenolone. This neuron also produces actively progesterone due to an increase of $3 \beta-H S D$ activity only during neonatal life. Allopregnanolone $(3 \alpha$, $5 \alpha$-tetrahydroprogesterone) is also metabolized by the enzymes $5 \alpha$-reductase and $3 \alpha-H S D$ from progesterone during neonatal life.
Estrogen formation in the Purkinje cell also occurs in the neonate because

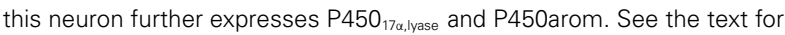
details. StAR, steroidogenic acute regulatory protein; P450scc,

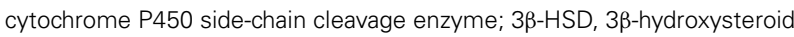
dehydrogenase/ $\Delta^{5}$ - $\Delta^{4}$-isomerase; $\mathrm{P} 40_{17 \alpha, \text { lyase }}$, cytochrome $\mathrm{P} 45017 \alpha$ -

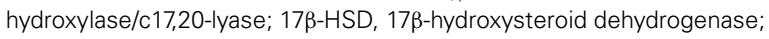
$3 \alpha$-HSD, $3 \alpha$-hydroxysteroid dehydrogenase; P450arom, cytochrome P450 aromatase. 
essential role in the process of memory and learning. In addition, this neuron expresses a key enzyme of estrogen formation, cytochrome $\mathrm{P} 450$ aromatase (P450arom), and actively produces estradiol in the neonate (Sakamoto et al., 2003a; Tsutsui et al., 2003b; Figure 1). Estradiol may also contribute to important events in the developing Purkinje cell (Sakamoto et al., 2003a; Sasahara et al., 2007).

\section{NEUROSTEROIDS PRODUCED IN THE PURKINJE CELL PREGNENOLONE}

Pregnenolone, a $3 \beta$-hydroxy- $\Delta^{5}$-steroid, is a main precursor of steroid hormones. The formation of pregnenolone is initiated by the cleavage of cholesterol side-chain by $\mathrm{P} 450 \mathrm{scc}$, a rate-limiting mitochondrial enzyme. The first immunohistochemical study in quail using an antibody against P450scc reported that the distribution of immunoreactive cell bodies and fibers was coincident with the location of somata and dendrites of Purkinje cells in the cerebellum (Tsutsui and Yamazaki, 1995; Usui et al., 1995). Western immunoblot analysis with the P450scc antibody confirmed the presence of P450scc in the cerebellum (Tsutsui and Yamazaki, 1995; Usui et al., 1995). It is considered that Purkinje cells possess $\mathrm{P} 450$ scc, because $\mathrm{P} 450$ scc immunoreactivity was restricted to this neuron in the cerebellum (Tsutsui and Yamazaki, 1995; Usui et al., 1995). These avian findings provided the first evidence for the location of P450scc in neurons in the brain.

Immunohistochemical studies of the rat cerebellum using an antibody to P450scc also showed immunoreaction confined to the somata and dendrites of Purkinje cells (Ukena et al., 1998). The Purkinje cells were identified by immunostaining with an antibody for the inositol trisphosphate $\left(\mathrm{IP}_{3}\right)$ receptor, a marker for Purkinje cells (Ukena et al., 1998). P450scc immunoreactivity was not observed in astrocytes, which were identified by immunoreaction to glial fibrillary acidic protein (GFAP). Interestingly, P450scc appeared in the rat Purkinje cell at its differentiation, and the expression of this enzyme persisted during neonatal development into adulthood (Ukena et al., 1998). In addition to higher vertebrates, Tsutsui and colleagues further identified P450scc in the Purkinje cell of amphibians (Takase et al., 1999). Taken together, these findings indicate that Purkinje cells possess P450scc and produce pregnenolone in vertebrates (Figure 1).

Steroidogenic acute regulatory protein (StAR) was also found in Purkinje cells (Furukawa et al., 1998; Figure 1). StAR is involved in the transport of cholesterol to the inner mitochondrial membrane, in which P450scc is localized, and thus plays a key role in acute steroid biosynthesis in peripheral steroidogenic glands (Clark et al., 1994). Therefore, StAR may also contribute to the regulation of pregnenolone formation in the Purkinje cell (Figure 1).

\section{PROGESTERONE AND ITS METABOLITE}

Progesterone is known to be a sex steroid hormone and acts on brain tissues through nuclear progesterone receptors (PR). Progesterone formation from cholesterol in the Purkinje cells has been demonstrated in the Purkinje cells, along with $3 \beta-H S D$, a membrane-bound mitochondrial enzyme that is responsible for the biosynthesis of progesterone from pregnenolone (Ukena et al., 1999). Tsutsui and colleagues found that Purkinje cells express not only P450scc (Ukena et al., 1998) but also 3ß-HSD (Ukena et al.,
1999; Figure 1). RT-PCR and biochemical techniques combined with high-performance liquid chromatography (HPLC) analysis showed the expression of $3 \beta-H S D$ and its enzymatic activity in the rat cerebellum (Ukena et al., 1999). Using in situ hybridization of $3 \beta$-HSD mRNA, the site of $3 \beta$-HSD expression was localized in Purkinje cells and external granule cells (Ukena et al., 1999). Thus, both P450scc and 3 $\beta$-HSD are expressed in Purkinje cells (Figure 1). The colocalization of P450scc and 3 $\beta$-HSD in external granule cells is still unclear. The expression of $3 \beta-\mathrm{HSD}$ in Purkinje cells was also evident in other vertebrates (Tsutsui et al., 1999; Sakamoto et al., 2001a). Surprisingly, the expression of $3 \beta$ HSD in the mammalian cerebellum increased during neonatal life (Ukena et al., 1999), unlike P450scc (Ukena et al., 1998). Such an age-dependent expression of $3 \beta$-HSD was confirmed by biochemical studies together with HPLC analysis, indicating an increase of progesterone formation during neonatal life (Ukena et al., 1999). Thus, this neuron actively produces progesterone as a product of an increase of $3 \beta$-HSD activity during neonatal life (Ukena et al., 1999; Figure 1).

Biochemical analysis together with HPLC and thin-layer chromatography (TLC) further revealed that the progesterone metabolite allopregnanolone is also found in the mammalian cerebellum during neonatal life (Tsutsui and Ukena, 1999; Tsutsui et al., 2003a,b, 2004; Figure 1). The expression of $5 \alpha$-reductase and $3 \alpha-$ HSD that metabolize progesterone to allopregnanolone has been found in the Purkinje cell (Agís-Balboa et al., 2006, 2007; Figure 1).

\section{ESTRADIOL}

Estradiol is also known to be a sex steroid and acts on brain tissues. P450arom is a key enzyme of estrogen formation in peripheral steroidogenic glands. Tsutsui and colleagues have further demonstrated the expression of P450arom in rat Purkinje cells during neonatal life (Sakamoto et al., 2003a; Figure 1). RT-PCR and in situ hybridization analyses showed that the expression of P450arom mRNA is restricted to Purkinje cells and external granule cells in the cerebellum in neonatal rats (Sakamoto et al., 2003a). A specific enzyme immunoassay for estradiol further indicated that cerebellar estradiol concentrations in the neonate are higher than those in prepubertal and adult rats (Sakamoto et al., 2003a). In addition, a recent study has shown the expression and activity of cytochrome P450 17 $\alpha$-hydroxylase/c17,20-lyase (P450 $17 \alpha$,lyase), which converts pregnenolone to dehydroepiandrosterone (DHEA) or progesterone to androstenedione, an immediate precursor of estrogen formed by P450arom, in the Purkinje cell (Matsunaga et al., 2001; Figure 1). These studies indicate estrogen formation in the Purkinje cell during neonatal life (Figure 1). Therefore, not only progesterone and its metabolite allopregnanolone but also estrogen may be synthesized in the developing Purkinje cell (Figure 1).

\section{POSSIBLE ACTIONS OF NEUROSTEROIDS PRODUCED IN THE PURKINJE CELL PROMOTION OF PURKINJE DENDRITIC GROWTH, SPINOGENESIS, AND SYNAPTOGENESIS}

It is well known that in the rat marked morphological changes occur in the cerebellum after birth during neonatal life and the formation of the cerebellar cortex completes in the neonate through 
the processes of migration of external granule cells, neuronal and glial growth, and synaptogenesis (Altman, 1972a,b). According to Altman and Bayer (1978), the rat Purkinje cell is prenatally formed and its maturation starts immediately after birth. Purkinje cells actively synthesize progesterone during the neonatal period, as the expression of $3 \beta$-HSD and its enzymatic activity increase in neonatal rats (Ukena et al., 1999; Figure 1). The progesterone metabolite allopregnanolone is also synthesized in the cerebellum of neonatal rats (Tsutsui and Ukena, 1999; Tsutsui et al., 2003b,c, 2004). Thus, cerebellar development is dramatic during neonatal life, when cerebellar concentrations of progesterone and allopregnanolone are high (Tsutsui and Ukena, 1999; Ukena et al., 1999; Tsutsui et al., 2003b). Therefore, progesterone and/or allopregnanolone may be involved in the formation of the cerebellar neuronal circuit by promoting neuronal growth and neuronal synaptic contact.

In vitro studies using cultured cerebellar slices of newborn rats showed that progesterone promotes dendritic growth and dendritic spine formation of the Purkinje cell (Sakamoto et al., 2001b, 2002; Figure 2). A similar result was obtained by in vivo studies (Sakamoto et al., 2001b, 2002). The stimulatory action of progesterone on Purkinje dendrites was completely blocked by a combined administration of the PR antagonist mifepristone (RU486) in vitro (Sakamoto et al., 2001b, 2002). Furthermore, in vivo administration of RU486 during the endogenous peak of progesterone inhibited dendritic growth and dendritic spine formation of the Purkinje cell (Sakamoto et al., 2001b, 2002). Electron microscopic analysis further revealed that progesterone induces an increase in the density of dendritic axospinous synapses on the Purkinje cell (Sakamoto et al., 2001b, 2002; Figure 2). In contrast, there was no significant change in the density of dendritic shaft synapses after progesterone administration (Sakamoto et al., 2001b, 2002). The effect of progesterone on Purkinje dendritic spine synapses was also blocked by RU486 (Sakamoto et al., 2001b, 2002). In contrast to progesterone, there was no significant effect of allopregnanolone on Purkinje dendritic growth, spinogenesis, and synaptogenesis (Sakamoto et al., 2001b, 2002). These results indicate that progesterone promotes the dendritic growth, spinogenesis, and synaptogenesis of Purkinje cells during cerebellar development (Figure 2). To draw a firm conclusion, however, further study is needed because RU486 is considered to be not a pure PR antagonist, but rather a PR modulator (Ghoumari et al., 2003).

Purkinje cells also express P450arom, a key enzyme of estrogen formation, highly in the neonate (Sakamoto et al., 2003a). Estradiol levels in the neonate are higher in the cerebellum than in the plasma (Sakamoto et al., 2003a). The effect of estradiol on dendritic growth of Purkinje cells was investigated in both in vitro and in vivo studies (Sakamoto et al., 2003a). Treatment of cerebellar cultures with estradiol promoted the dendritic growth of Purkinje cells in a dose-dependent manner with active doses being in physiological levels of estradiol measured in the cerebellum (Sakamoto et al., 2003a; Figure 3). A similar morphological effect was also obtained by the in vivo treatment with estradiol (Sakamoto et al., 2003a; Figure 3). In contrast, the blockage of action of endogenous estrogen by a treatment with tamoxifen, an estrogen receptor antagonist, had reversed effects on the morphology of Purkinje cells. Further, estradiol treatment increased the

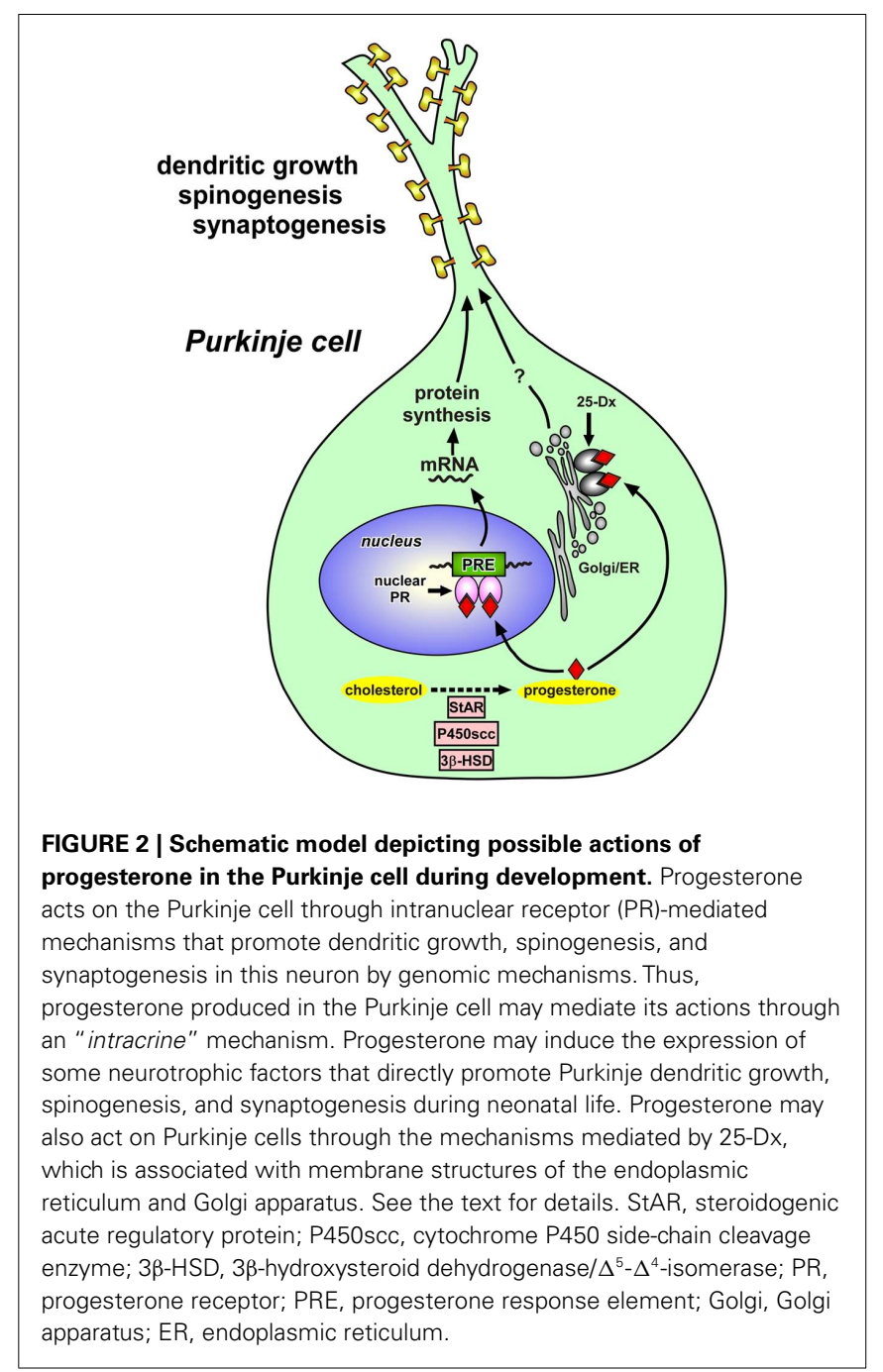

densities of Purkinje dendritic spines (Sakamoto et al., 2003a) and spine synapses (Sasahara et al., 2007; Figure 3). These effects were also inhibited by tamoxifen (Sakamoto et al., 2003a; Sasahara et al., 2007). Thus, estradiol also promotes the dendritic growth, spinogenesis, and synaptogenesis of Purkinje cells (Figure 3). These estrogen actions were confirmed by the study using P450arom knock-out (ArKO) mice (Sasahara et al., 2007) as described in Section "Functional Significance of Neurosteroids Produced in the Purkinje Cell."

On the other hand, DHEA is also known to be an abundant neurosteroid in the mammalian brain (Corpéchot et al., 1981, 1983; Jo et al., 1989). Compagnone and Mellon (1998) reported a similar action of DHEA and its sulfate ester (DHEAS) on neuronal growth using primary cultures of mouse embryonic neocortical neurons. According to Compagnone and Mellon (1998), DHEA selectively increased the length of axons and the incidence of varicosities and basket-like process formations in vitro, whereas DHEAS selectively promoted branching and dendritic growth in vitro. Therefore, neurosteroids may play an important role in cortical organization in both the mammalian cerebellum and cerebrum during development. 


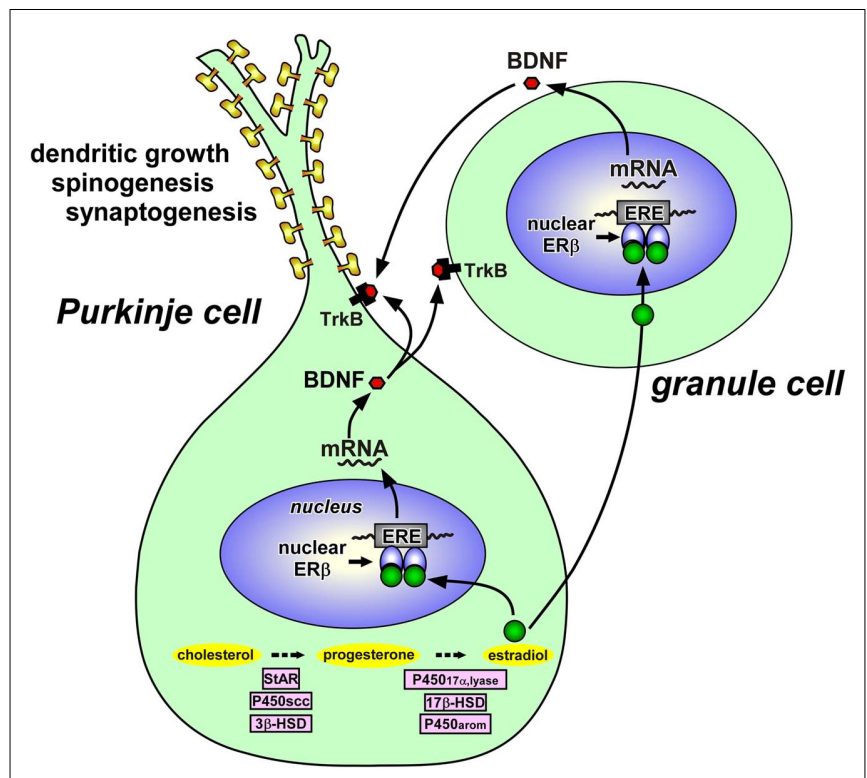

FIGURE 3 | Schematic model depicting possible actions of estradiol in the Purkinje cell during development. Estradiol acts on the Purkinje cell through intranuclear receptor (ER $\beta)$-mediated mechanisms that promote dendritic growth, spinogenesis, and synaptogenesis in this neuron by genomic mechanisms. Both Purkinje cells and granule cells express BDNF and TrkB, a receptor for BDNF. Estradiol induces the expression of BDNF, which may act on Purkinje cells and granule cells through TrkB-mediated mechanisms to promote Purkinje dendritic growth, spinogenesis, and synaptogenesis. See the text for details. StAR, steroidogenic acute regulatory protein; $\mathrm{P} 450 \mathrm{scc}$, cytochrome $\mathrm{P} 450$ side-chain cleavage enzyme;

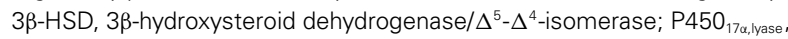
cytochrome P450 17 $\alpha$-hydroxylase/c17,20-lyase; 17 $\beta$-HSD,

$17 \beta$-hydroxysteroid dehydrogenase; P450arom, cytochrome P450 aromatase; $E R \beta$, estrogen receptor- $\beta$; ERE, estrogen response element; BDNF, brain-derived neurotrophic factor; TrkB, BDNF receptor.

\section{NEUROPROTECTION OF PURKINJE CELLS}

In addition to organizing actions of progesterone as described above, it has been reported that RU486 protects Purkinje cells from developmental cell death, although progesterone does not possess any effect on Purkinje cell survival (Ghoumari et al., 2003). This protective effect of RU486 is considered to be independent of the activation of nuclear PR (Ghoumari et al., 2003).

It has been shown that allopregnanolone is involved in Purkinje and granule cell survival (Griffin et al., 2004; Figure 2), although allopregnanolone failed to promote the dendritic growth, spinogenesis, and synaptogenesis of Purkinje cells (Sakamoto et al., 2001b, 2002). The Niemann-Pick type C (NP-C) mouse has been used as an excellent animal model for understanding the action of allopregnanolone. NP-C is an autosomal recessive, childhood neurodegenerative disease characterized by defective intracellular cholesterol trafficking, resulting in Purkinje cell degeneration as well as neuronal degeneration in other regions. Brains from adult NP-C mice contained less allopregnanolone than wild-type (WT) brain (Griffin et al., 2004). Administration of allopregnanolone to neonatal NP-C mice increased Purkinje cell survival and delayed neurodegeneration (Griffin et al., 2004; Figure 4).

\section{Formation of Cerebellar Neuronal Circuit}

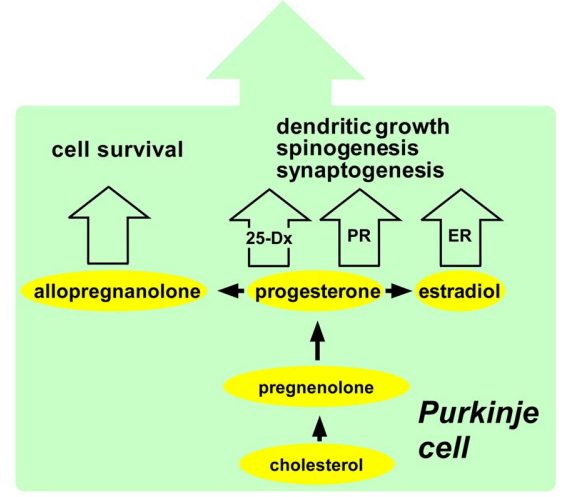

FIGURE 4 | Summary of possible actions of neurosteroids in the Purkinje cell during development. The Purkinje cell actively synthesizes progesterone, allopregnanolone, and estradiol from cholesterol during neonatal life when cerebellar neuronal circuit formation occurs in mammals. Progesterone acts on the Purkinje cell through intranuclear receptor (PR)-mediated mechanisms that promote dendritic growth, spinogenesis, and synaptogenesis in this neuron by genomic mechanisms. Progesterone may also promote dendritic growth, spinogenesis, and synaptogenesis via 25-Dx as well as its nuclear receptor in the Purkinje cell in the neonate. Estradiol acts on the Purkinje cell through intranuclear receptor (ER)-mediated mechanisms that promote dendritic growth, spinogenesis, and synaptogenesis in this neuron by genomic mechanisms.

Allopregnanolone is involved in Purkinje cell survival. See the text for details. PR, progesterone receptor; ER, estrogen receptor.

\section{MODE OF ACTION OF NEUROSTEROIDS PRODUCED IN THE PURKINJE CELL \\ MODE OF PROGESTERONE ACTION}

To elucidate the mode of action of progesterone, the expression of $\mathrm{PR}$ in the cerebellum was then characterized in neonatal rats. Interestingly, intranuclear PR-A and PR-B were expressed in the Purkinje cell (Sakamoto et al., 2001b, 2002, 2003b; Figure 2). It is therefore considered that progesterone acts directly on Purkinje cells through intranuclear receptor-mediated mechanisms to promote Purkinje dendritic growth, spinogenesis, and synaptogenesis during neonatal development (Sakamoto et al., 2001b, 2002, 2003b; Figure 2). Such genomic actions of progesterone may be essential for the formation of cerebellar neuronal circuit (Figure 4). Thus, progesterone produced in the Purkinje cell may mediate its actions through an "intracrine" mechanism (Figure 2). In addition to the central nervous system, progesterone has also been shown to promote myelination in the peripheral nervous system via nuclear PR (Koenig et al., 1995; Chan et al., 2000).

Interestingly, Purkinje cells also express the putative membrane PR, 25-Dx, during neonatal life (Sakamoto et al., 2004; Figure 2). RT-PCR and Western immunoblot analyses revealed the expressions of 25-Dx and its mRNA in the rat cerebellum, which increased during neonatal life (Sakamoto et al., 2004). By immunocytochemistry, the expression of 25-Dx was localized in the Purkinje cell and external granule cell layer (Sakamoto et al., 2004). 25-Dx immunoreactivity was associated with membrane structures of the endoplasmic reticulum and Golgi apparatus in the Purkinje cell (Sakamoto et al., 2004). Accordingly, progesterone 
may promote dendritic growth, spinogenesis, and synaptogenesis via 25-Dx as well as its nuclear receptor in the Purkinje cell in the neonate (Sakamoto et al., 2008; Figure 2). This protein is now named "progesterone receptor membrane component1" (PGRMC1), and there is now strong evidence that PGRMC1 mediates the anti-apoptotic actions of progesterone in both rat granulose and luteal cells and it associates with another membrane protein, such as plasminogen activator inhibitor RNA-binding protein-1 (PAIRBP1; Engmann et al., 2006; Peluso et al., 2006; Cahill, 2007). Future study is needed to demonstrate whether the promotion of Purkinje dendritic growth, spinogenesis, and synaptogenesis by progesterone is due to both genomic and non-genomic actions.

It is known that neurotrophins are attractive candidate regulators of Purkinje dendrite and spine development. It has been reported that neurotrophic factors, such as brain-derived neurotrophic factor (BDNF) and neurotrophin-3 (NT-3), are highly expressed in the developing cerebellum and are critical for proper development of Purkinje cells and granule cells (Rocamora et al., 1993; Ernfors et al., 1994; Schwartz et al., 1997; Bates et al., 1999). Therefore, progesterone may induce the expression of some neurotrophic factors that directly promote Purkinje dendritic growth, spinogenesis, and synaptogenesis during neonatal life (for reviews, see Tsutsui, 2008a,b, 2009; Figure 2).

\section{MODE OF ESTROGEN ACTION}

It has been reported that in the neonatal rat, Purkinje cells express estrogen receptor- $\beta$ (ER $\beta$; Price and Handa, 2000; Jakab et al., 2001; Figure 3). Therefore, it is likely that estradiol acts directly on Purkinje cells through intranuclear ER $\beta$-mediated mechanisms (Figure 3). This hypothesis was confirmed by the study using the ER antagonist tamoxifen, which inhibited the effects of estrogen on Purkinje dendritic growth, spinogenesis, and synaptogenesis (Sakamoto et al., 2003a; Sasahara et al., 2007). It is known that this anti-estrogen binds to ERs (ER $\alpha$ and $E R \beta)$ and activates transcription via activating protein-1 response elements (Webb et al., 1995) but blocks transcriptional activation through the classical estrogen response element and not producing any agonist effect via this pathway (McDonnell et al., 1995; Paech et al., 1997). Thus, it is considered that the anti-estrogen tamoxifen blocks transcriptional activation of ER $\beta$ in the developing Purkinje cell. On the other hand, granule cells also express ER $\beta$ (Price and Handa, 2000; Jakab et al., 2001; Figure 3). Involvement of ER $\beta$ in the brain function has also been reported in the rat hypothalamus (Orikasa et al., 2002; Ikeda et al., 2003).

While ER $\beta$ appears to mediate the effects of estradiol on Purkinje cell function, other receptors may also mediate the effects of estradiol on other brain regions, such as hippocampus (Gould et al., 1990; Woolley et al., 1990; Woolley and McEwen, 1994; Murphy and Segal, 1996; McEwen et al., 2001) and hypothalamus (Pérez et al., 1993). The effect of estradiol on hippocampal CA1 pyramidal cell dendrite spine density requires the activation of $N$-methyl-D-aspartate (NMDA) receptors in adult female rats (Woolley and McEwen, 1994). Such non-genomic estrogen actions may lead to alterations in gene expression. Hence, NMDA receptors may also mediate estradiol action in Purkinje cells. Further studies are needed to draw a firm conclusion.
To understand the mode of action of estradiol, Tsutsui and colleague further examined the expression of BDNF and NT-3 in response to estrogen actions in the neonate (Sasahara et al., 2007), because these neurotrophic factors are known to be critical for proper development of Purkinje cells (Rocamora et al., 1993; Ernfors et al., 1994; Schwartz et al., 1997; Bates et al., 1999). Estrogen administration to neonatal WT mice or ArKO mice increased the BDNF level in the cerebellum, whereas the anti-estrogen tamoxifen decreased the BDNF level in WT mice similar to ArKO mice (Sasahara et al., 2007). BDNF administration to tamoxifen-treated WT mice increased Purkinje dendritic growth (Sasahara et al., 2007). In contrast to BDNF, estrogen administration did not influence the level of NT-3 in the cerebellum (Sasahara et al., 2007). The NT-3 level did not change in ArKO mice as well (Sasahara et al., 2007). These results indicate that BDNF mediates estrogen action on the promotion of dendritic growth, spinogenesis, and synaptogenesis in the Purkinje cell during neonatal development (Figure 3).

Importantly, the gene encoding BDNF contains a sequence similar to the canonical estrogen response element found in estrogen-target genes (Sohrabji et al., 1995). In addition, BDNF increases levels of synaptic vesicle proteins, such as synaptophysin and synapsin 1, which are reliable markers of synaptogenesis, in the spinal neurons (Wang et al., 1995). Estrogen increases presynaptic and postsynaptic proteins, such as syntaxin, synaptophysin, and spinophilin, in the CA1 region of the primate hippocampus (Choi et al., 2003). Furthermore, it has been reported that estrogen treatment induces these synaptic proteins in the CA1 region of hippocampus, and this effect is blocked by CI628, an antiestrogen of the tamoxifen type (Brake et al., 2001). The expression of P450arom mRNA in the cerebellum is restricted to Purkinje cells and external granule cells in the neonatal rats (Sakamoto et al., 2003a; Tsutsui, 2006a,b; Tsutsui and Mellon, 2006). Both Purkinje cells and granule cells express BDNF (Hofer et al., 1990; Borghesani et al., 2002) and TrkB, a receptor for BDNF (Klein et al., 1990; Segal et al., 1995; Carter et al., 2002; Figure 3). It is therefore likely that estrogen induces the expression of BDNF, which acts on Purkinje cells and granule cells through TrkB-mediated mechanisms to promote Purkinje dendritic growth, spinogenesis, and synaptogenesis during neonatal life (Sasahara et al., 2007; Tsutsui, 2008b, 2009; Figure 3).

\section{FUNCTIONAL SIGNIFICANCE OF NEUROSTEROIDS PRODUCED IN THE PURKINJE CELL}

To demonstrate the functional significance of endogenous estradiol in the Purkinje cell during neonatal life, estrogen actions on dendritic growth, spinogenesis and synaptogenesis in Purkinje cells were investigated using ArKO mice (Sasahara et al., 2007). ArKO mice used in the study lack exons 1 and 2 and the proximal promoter region of the P450arom gene cyp19 (cytochrome P450, family 19; Honda et al., 1998). Estradiol deficiency in ArKO mice decreased dendritic growth, spinogenesis, and synaptogenesis in Purkinje cells in the neonate (Sasahara et al., 2007). In addition, administration of estradiol to ArKO mice increased Purkinje dendritic growth, spinogenesis, and synaptogenesis (Sasahara et al., 2007). These results indicate physiological actions of endogenous estrogen on the promotion of dendritic growth, spinogenesis, and synaptogenesis in the Purkinje cell during neonatal development. 
Neuroprotective and neurotrophic actions of estrogen on other brain regions have been reported by the studies using ArKO mice (Azcoitia et al., 1999; Carswell et al., 2005). Neuroprotective effects of estrogen on dentate gyrus neurons in the hippocampus were mediated by estrogen-induced insulin-like growth factor-1 (IGF1; Azcoitia et al., 1999), similar to neurotrophic effects of estrogen on Purkinje cells mediated by estrogen-induced BDNF (Sasahara et al., 2007).

In addition to the analysis of biological actions of endogenous estradiol using ArKO mice, we need to elucidate the functional significance of endogenous progesterone in the Purkinje cell during neonatal life. To demonstrate the functional significance of endogenous progesterone, the analysis of progesterone actions on Purkinje dendritic growth, spinogenesis, and synaptogenesis using $3 \beta$-HSD knock-out mice is now in progress.

Progesterone and allopregnanolone have neurotrophic and neuroprotective effects and may improve cognitive function in mammals (Schumacher et al., 2003; Frye and Walf, 2008). Estradiol is also implicated in the cognitive processes of the mammalian brain (Jacobs et al., 1998; Drake et al., 2000; Hao et al., 2007). Several regions of the mammalian brain involved in memory and cognition, such as the cerebellar cortex, hippocampus, amygdala, and cerebral cortex, are rich in ERs (Price and Handa, 2000; Shughrue et al., 2000; Jakab et al., 2001; Sakamoto et al., 2003a; Tsutsui et al., 2004; Sasahara et al., 2007). Thus, it is considered that progesterone, allopregnanolone, and estradiol alter the processes of memory and cognition mediated by the cerebellar cortex, hippocampus, and cerebral cortex.

\section{REFERENCES}

Agís-Balboa, R. C., Pinna, G., Pibiri, F., Kadriu, B., Costa, E., and Guidotti, A. (2007). Down-regulation of neurosteroid biosynthesis in corticolimbic circuits mediates social isolationinduced behavior in mice. Proc. Natl. Acad. Sci. U.S.A. 104, 18736-18741.

Agís-Balboa, R. C., Pinna, G., Zhubi, A., Maloku, E., Veldic, M., Costa, E., and Guidotti, A. (2006). Characterization of brain neurons that express enzymes mediating neurosteroid biosynthesis. Proc. Natl. Acad. Sci. U.S.A. 103, 14602-14607.

Altman, J. (1972a). Postnatal development of the cerebellar cortex in the rat. I. The external germinal layer and the transitional molecular layer. J. Comp. Neurol. 145, 353-397.

Altman, J. (1972b). Postnatal development of the cerebellar cortex in the rat. II. Phases in the maturation of Purkinje cells and of the molecular layer. J. Comp. Neurol. 145, 399-463.

Altman, J., and Bayer, S. A. (1978). Prenatal development of the cerebellar system in the rat. I. Cytogenesis and histogenesis of the deep nuclei and the cortex of the cerebellum. J. Comp. Neurol. 179, 23-48.
Azcoitia, I., Sierra, A., and GarciaSegura, L. M. (1999). Neuroprotective effects of estradiol in the adult rat hippocampus: interaction with insulin-like growth factorI signalling. J. Neurosci. Res. 58, 815-822.

Bates, B., Rios, M., Trumpp, A., Chen, C., Fan, G., Bishop, J. M., and Jaenisch, R. (1999). Neurotrophin3 is required for proper cerebellar development. Nat. Neurosci. 2, 115-117.

Baulieu, E.-E. (1997). Neurosteroids: of the nervous system, by the nervous system, for the nervous system. Recent Prog. Horm. Res. 52, 1-32.

Borghesani, P. R., Peyrin, J. M., Klein, R., Rubin, J., Carter, A. R., Schwartz, P. M., Luster, A., Corfas, G., and Segal, R. A. (2002). BDNF stimulates migration of cerebellar granule cells. Development 129, 1435-1442.

Brake, W. G., Alves, S. E., Dunlop, J. C., Lee, S. J., Bulloch, K., Allen, P. B., Greengard, P., and McEwen, B. S. (2001). Novel target sites for estrogen action in the dorsal hippocampus: an examination of synaptic proteins. Endocrinology $142,1284-1289$.

\section{CONCLUSION AND FUTURE DIRECTIONS}

Purkinje cell is a major site for neurosteroid formation in the brain. This neuron actively synthesizes progesterone and allopregnanolone, a progesterone metabolite, from cholesterol during neonatal life when cerebellar neuronal circuit formation occurs in mammals. This neuron also produces estradiol in the neonate. Both progesterone and estradiol promote Purkinje dendritic growth, spinogenesis, and synaptogenesis. Allopregnanolone is also considered to be involved in Purkinje and granule cell survival. These neurosteroid actions may be essential for the formation of the cerebellar neuronal circuit as summarized in Figure 4.

The discovery of Purkinje cell as a major site for neurosteroid formation has improved our understanding of neuronal neurosteroidogenesis and biological actions of neurosteroids in the cerebellum. This exciting area of research should focus on physiological roles of neurosteroids in the future, because Purkinje cells play an important role in the process of memory and learning. Therefore, behavioral studies using neurosteroidogenic enzyme knock-out animals and electrophysiological studies on the occurrence of long-term potentiation and/or long-term depression are needed.

\section{ACKNOWLEDGMENTS}

The author thanks Mariko Usui, Hanako Shikimi, Katsunori Sasahara, Asami Sekine, Shin-ichiro Honda, Nobuhiro Harada, and Mitsuhiro Kawata for their work cited in this manuscript. This work was supported by Grants-in-Aid for Scientific Research from the Ministry of Education, Science, and Culture, Japan (18107002, 22132004, and 22227002 to Kazuyoshi Tsutsui).

Cahill, M. A. (2007). Progesterone receptor membrane component 1 : an integrative review. J. Steroid Biochem. Mol. Biol. 105, 16-36.

Carswell, H. V., Dominiczak, A. F., Garcia-Segura, L. M., Harada, N., Hutchison, J. B., and Macrae, I. M. (2005). Brain aromatase expression after experimental stroke: topography and time course. J. Steroid Biochem. Mol. Biol. 96, 89-91.

Carter, A. R., Chen, C., Schwartz, P. M., and Segal, R. A. (2002). Brainderived neurotrophic factor modulates cerebellar plasticity and synaptic ultrastructure. J. Neurosci. 22, 1316-1327.

Chan, J. R., Rodriguez-Waitkus, P. M. Ng, B. K., Liang, P., and Glaser, M. (2000). Progesterone synthesized by Schwann cells during myelin formation regulates neuronal gene expression. Mol. Biol. Cell 11, 2283-2295.

Choi, J. M., Romeo, R. D., Brake, W. G., Bethea, C. L., Rosenwaks, Z., and McEwen, B. S. (2003). Estradiol increases pre- and post-synaptic proteins in the CA1 region of the hippocampus in female rhesus macaques (Macaca mulatta). Endocrinology 144, 4734-4738.
Clark, B. J., Wells, J., King, S. R., and Stocco, D. M. (1994). The purification, cloning, and expression of a novel luteinizing hormone-induced mitochondrial protein in MA-10 mouse Leydig tumor cells. Characterization of the steroidogenic acute regulatory protein (StAR). J. Biol. Chem. 269, 28314-28322.

Compagnone, N. A., and Mellon, S. H. (1998). Dehydroepiandrosterone: a potential signalling molecule for neocortical organization during development. Proc. Natl. Acad. Sci. U.S.A. 95, 4678-4683.

Compagnone, N. A., and Mellon, S. H. (2000). Neurosteroids: biosynthesis and function of these novel neuromodulators. Front. Neuroendocrinol. 21, 1-56.

Corpéchot, C., Robel, P., Axelson, M., Sjövall, J., and Baulieu, E.-E. (1981). Characterization and measurement of dehydroepiandrosterone sulfate in rat brain. Proc. Natl. Acad. Sci. U.S.A. 78, 4704-4707.

Corpéchot, C., Synguelakis, M., Talha, S., Axelson, M., Sjövall, J., Vihko, R., Baulieu, E.-E., and Robel, P. (1983). Pregnenolone and its sulfate ester in rat brain. Brain Res. 270, 119-125. 
Drake, E. B., Henderson, V. W., Stanczyk, F. Z., McCleary, C. A., Brown, W. S., Smith, C. A., Rizzo, A. A., Murdock, G. A., and Buckwalter, J. G. (2000). Associations between circulating sex steroid hormones and cognition in normal elderly women. Neurology 54, 599-603.

Engmann, L., Losel, R., Wehling, M., and Peluso, J. J. (2006). Progesterone regulation of human granulosa/luteal cell viability by an RU486-independent mechanism. J. Clin. Endocrinol. Metab. 91, 4962-4968.

Ernfors, P., Lee, K. F., and Jaenisch, R. (1994). Mice lacking brainderived neurotrophic factor develop with sensory deficits. Nature 368, 147-150.

Frye, C. A., and Walf, A. A. (2008). Effects of progesterone administration and APPswe+PSEN $1 \Delta \mathrm{e} 9$ mutation for cognitive performance of mid-aged mice. Neurobiol. Learn. Mem. 89, 17-26.

Furukawa, A., Miyatake, A., Ohnishi, T., and Ichikawa, Y. (1998). Steroidogenic acute regulatory protein (StAR) transcripts constitutively expressed in the adult rat central nervous system: colocalization of StAR, cytochrome P-450scc (CYP

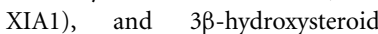
dehydrogenase in the rat brain. $J$. Neurochem. 71, 2231-2238.

Ghoumari, A. M., Dusart, I., El-Etr, M., Tronche, F., Sotelo, C., Schumacher, M., and Baulieu, E.-E. (2003). Mifepristone (RU486) protects Purkinje cells from cell death in organotypic slice cultures of postnatal rat and mouse cerebellum. Proc. Natl. Acad. Sci. U.S.A. 100, 7953-7958.

Gould, E., Woolley, C. S., Frankfurt, M., and McEwen, B. S. (1990). Gonadal steroids regulate dendritic spine density in hippocampal pyramidal cells in adulthood. J. Neurosci. 10, 1286-1291.

Griffin, L. D., Gong, W., Verot, L., and Mellon, S. H. (2004). Niemann-Pick type $\mathrm{C}$ disease involves disrupted neurosteroidogenesis and responds to allopregnanolone. Nat. Med. 10, 704-711.

Hao, J., Rapp, P. R., Janssen, W. G., Lou, W., Lasley, B. L., Hof, P. R., and Morrison, J. H. (2007). Interactive effects of age and estrogen on cognition and pyramidal neurons in monkey prefrontal cortex. Proc. Natl. Acad. Sci. U.S.A. 104, 11465-11470.

Hofer, M., Pagliusi, S. R., Hohn, A., Leibrock, J., and Barde, Y. A. (1990). Regional distribution of brain-derived neurotrophic factor
mRNA in the adult mouse brain. EMBO J. 9, 2459-2464.

Honda, S., Harada, N., Ito, S., Takagi, Y., and Maeda, S. (1998). Disruption of sexual behavior in male aromatasedeficient mice lacking exons 1 and 2 of the cyp19 gene. Biochem. Biophys. Res. Commun. 252, 445-449.

Ikeda, Y., Nagai, A., Ikeda, M. A., and Hayashi, S. (2003). Sexually dimorphic and estrogen-dependent expression of estrogen receptor beta in the ventromedial hypothalamus during rat postnatal development. Endocrinology 144, 5098-5115.

Jacobs, D. M., Tang, M. X., Stern, Y., Sano, M., Marder, K., Bell, K. L., Schofield, P., Dooneief, G., Gurland, B., and Mayeux, R. (1998). Cognitive function in nondemented older women who took estrogen after menopause. Neurology 50, 368-373.

Jakab, R. L., Wong, J. K., and Belcher, S. M. (2001). Estrogen receptor $\beta$ immunoreactivity in differentiating cells of the developing rat cerebellum. J. Comp. Neurol. 430, 396-409.

Jo, D. H., Abdallah, M. A., Young, J., Baulieu, E.-E., and Robel, P. (1989). Pregnenolone, dehydroepiandrosterone, and their sulfate and fatty acid esters in the rat brain. Steroids 54, 287-297.

Klein, R., Parada, L. F., Coulier, F., and Barbacid, M. (1990). TrkB, a novel tyrosine protein kinase receptor expressed during mouse neural development. $E M B O \mathrm{~J} .8$, 3701-3709.

Koenig, H. L., Schumacher, M., Ferzaz, B., Thi, A. N., Ressouches, A., Guennoun, R., Jung-Testas, I., Robel, P., Akwa, Y., and Baulieu, E.-E. (1995). Progesterone synthesis and myelin formation by Schwann cells. Science 268, 1500-1503.

Matsunaga, M., Ukena, K., and Tsutsui, K. (2001). Expression and localization of cytochrome P450 17 $\alpha$ hydroxylase/c17, 20-lyase in the avian brain. Brain Res. 899, 112-122.

McDonnell, D. P., Clemm, D. L., Hermann, T., Goldman, M. E., and Pike, J. W. (1995). Analysis of estrogen receptor function in vitro reveals three distinct classes of antiestrogens. Mol. Endocrinol. 9, 659-669.

McEwen, B., Akama, K., Alves, S., Brake, W. G., Bulloch, K., Lee, S., Li, C., Yuen, G., and Milner, T. A. (2001). Tracking the estrogen receptor in neurons: implications for estrogen-induced synapse formation. Proc. Natl. Acad. Sci. U.S.A. 98, 7093-7100.

Mellon, S. H., and Deschepper, C. F. (1993). Neurosteroid biosynthesis: genes for adrenal steroidogenic enzymes are expressed in the brain. Brain Res. 629, 283-292.

Murphy, D. D., and Segal, M. (1996). Regulation of dendritic spine density in cultured rat hippocampal neurons by steroid hormones. J. Neurosci. 16, 4059-4068.

Orikasa, C., Kondo, Y., Hayashi, S., McEwen, B. S., and Sakuma, Y. (2002). Sexually dimorphic expression of estrogen receptor beta in the anteroventral periventricular nucleus of the rat preoptic area: implication in luteinizing hormone surge. Proc. Natl. Acad. Sci. U.S.A. 99, 3306-3309.

Paech, K., Webb, P., Kuiper, G. G., Nilsson, S., Gustafsson, J., Kushner, P. J., and Scanlan, T. S. (1997). Differential ligand activation of estrogen receptors $\mathrm{ER} \alpha$ and $\mathrm{ER} \beta$ at $\mathrm{AP} 1$ sites. Science 277, 1508-1510.

Peluso, J. J., Pappalardo, A., Losel, R., and Wehling, M. (2006). Progesterone membrane receptor component 1 expression in the immature rat ovary and its role in mediating progesterone's antiapoptotic action. Endocrinology 147, 3133-3140.

Pérez, J., Luquín, S., Naftolin, F., and García-Segura, L. M. (1993). The role of estradiol and progesterone in phased synaptic remodelling of the rat arcuate nucleus. Brain Res. 608 , 38-44.

Price, R. H., and Handa, R. J. (2000). Expression of estrogen receptor- $\beta$ protein and mRNA in the cerebellum of the rat. Neurosci. Lett. 288, 115-118.

Rocamora, N., García-Ladona, F. J., Palacios, J. M., and Mengod, G. (1993). Differential expression of brain-derived neurotrophic factor, neurotrophin-3, and low-affinity nerve growth factor receptor during the postnatal development of the rat cerebellar system. Brain Res. Mol. Brain Res. 17, 1-8.

Sakamoto, H., Mezaki, Y., Shikimi, H., Ukena, K., and Tsutsui, K. (2003a). Dendritic growth and spine formation in response to estrogen in the developing Purkinje cell. Endocrinology 144, 4466-4477.

Sakamoto, H., Shikimi, H., Ukena, K., and Tsutsui, K. (2003b). Neonatal expression of progesterone receptor isoforms in the cerebellar Purkinje cell in rats. Neurosci. Lett. 343, 163-166.

Sakamoto, H., Ukena, K., Kawata, M., and Tsutsui, K. (2008). Expression, localization and possible actions of 25-Dx, a membraneassociated putative progesterone-binding protein, in the developing Purkinje cell of the cerebellum: a new insight into the biosynthesis, metabolism and multiple actions of progesterone as a neurosteroid. Cerebellum 7, 18-25.

Sakamoto, H., Ukena, K., Takemori, H., Okamoto, M., Kawata, M., and Tsutsui, K. (2004). Expression and localization of 25-Dx, a membraneassociated putative progesteronebinding protein, in the developing Purkinje cell. Neuroscience 126, 325-334.

Sakamoto, H., Ukena, K., and Tsutsui, K. (2001a). Activity and localization of $3 \beta$-hydroxysteroid dehydrogenase $/ \Delta^{5}-\Delta^{4}$-isomerase in the zebrafish central nervous system. J. Comp. Neurol. 439, 291-305.

Sakamoto, H., Ukena, K., and Tsutsui, K. (2001b). Effects of progesterone synthesized de novo in the developing Purkinje cell on its dendritic growth and synaptogenesis. J. Neurosci. 21, 6221-6232.

Sakamoto, H., Ukena, K., and Tsutsui, K. (2002). Dendritic spine formation in response to progesterone synthesized de novo in the developing Purkinje cell in rats. Neurosci. Lett. 322, 111-115.

Sasahara, K., Shikimi, H., Haraguchi, S., Sakamoto, H., Honda, S., Harada, N., and Tsutsui, K. (2007). Mode of action and functional significance of estrogen-inducing dendritic growth, spinogenesis, and synaptogenesis in the developing Purkinje cell. J. Neurosci. 277, 408-7417.

Schumacher, M., Weill-Engerer, S., Liere, P., Robert, F., Franklin, R. J., Garcia-Segura, L. M., Lambert, J. J., Mayo, W., Melcangi, R. C., Parducz, A., Suter, U., Carelli, C., Baulieu, E.-E., and Akwa, Y. (2003). Steroid hormones and neurosteroids in normal and pathological aging of the nervous system. Prog. Neurobiol. 71, 3-29.

Schwartz, P. M., Borghesani, P. R., Levy, R. L., Pomeroy, S. L., and Segal R. A. (1997). Abnormal cerebellar development and foliation in $B D N F^{-I-}$ mice reveals a role for neurotrophins in CNS patterning. Neuron 19, 269-281.

Segal, R. A., Pomeroy, S. L., and Stiles, C. D. (1995). Axonal growth and fasciculation linked to differential expression of BDNF and NT3 receptors in developing cerebellar granule cells. J. Neurosci. 15, 4970-4981.

Shughrue, P. J., Scrimo, P. J., and Merchenthaler, I. (2000). Estrogen binding and estrogen receptor characterization (ER $\alpha$ and ER $\beta$ ) in the cholinergic neurons of the rat basal forebrain. Neuroscience 96 , 41-49. 
Sohrabji, F., Miranda, R. C., and Toran-Allerand, C. D. (1995). Identification of a putative estrogen response element in the gene encoding brain-derived neurotrophic factor. Proc. Natl. Acad. Sci. U.S.A. 92, 11110-11114.

Takase, M., Ukena, K., Yamazaki, T., Kominami, S., and Tsutsui, K. (1999). Pregnenolone, pregnenolone sulfate and cytochrome P450 side-chain cleavage enzyme in the amphibian brain and their seasonal changes. Endocrinology 140, 1936-1944.

Tsutsui, K. (2006a). Biosynthesis and organizing action of neurosteroids in the developing Purkinje cell. Cerebellum 5, 89-96.

Tsutsui, K. (2006b). Biosynthesis, mode of action and functional significance of neurosteroids in the developing Purkinje cell. J. Steroid Biochem. Mol. Biol. 102, 187-194.

Tsutsui, K. (2008a). Progesterone biosynthesis and action in the developing neuron. Endocrinology 149, 2757-2761.

Tsutsui, K. (2008b). Neurosteroids in the Purkinje cell: biosynthesis, mode of action and functional significance. Mol. Neurobiol. 37, 116-125.

Tsutsui, K. (2009). Neurosteroid biosynthesis and action in the Purkinje cell. J. Exp. Neurosci. 2, 1-12.

Tsutsui, K., Matsunaga, M., and Ukena, K. (2003a). Biosynthesis and biological actions of neurosteroids in the avian brain. Avian Poult. Biol. Rev. 14, 63-78.

Tsutsui, K., Sakamoto, H., and Ukena, K. (2003b). Biosynthesis and action of neurosteroids in the cerebellar Purkinje neuron. J. Steroid Biochem. Mol. Biol. 85, 311-321.

Tsutsui, K., Ukena, K., and Sakamoto, H. (2003c). A novel aspect of the cerebellum: biosynthesis of neurosteroids in the Purkinje cell. Cerebellum 2, 215-222.

Tsutsui, K., and Mellon, S. H. (2006). Neurosteroids in the brain neuron: biosynthesis, action and medicinal impact on neurodegenerative disease. Cent. Nerv. Syst. Agents Med. Chem. 6, 73-82.

Tsutsui, K., Sakamoto, H., Shikimi, H., and Ukena, K. (2004). Organizing actions of neurosteroids in the Purkinje neuron. Neurosci. Res. 49, 273-279.

Tsutsui, K., and Ukena, K. (1999). Neurosteroids in the cerebellar Purkinje neuron and their actions. Int. J. Mol. Med. 4, 49-56.

Tsutsui, K., Ukena, K., Takase, M. Kohchi, C., and Lea, R. W. (1999). Neurosteroid biosynthesis in vertebrate brains. Comp. Biochem. Physiol. C Pharmacol. Toxicol. Endocrinol. 124, 121-129.

Tsutsui, K., and Yamazaki, T. (1995). Avian neurosteroids. I. Preg- nenolone biosynthesis in the quail brain. Brain Res. 678, 1-9.

Ukena, K., Kohchi, C., and Tsutsui, K. (1999). Expression and activity of $3 \beta$-hydroxysteroid dehydrogenase/ $\Delta^{5}-\Delta^{4}$ - isomerase in the rat Purkinje neuron during neonatal life. Endocrinology 140, 805-813.

Ukena, K., Usui, M., Kohchi, C., and Tsutsui, K. (1998). Cytochrome P450 side-chain cleavage enzyme in the cerebellar Purkinje neuron and its neonatal change in rats. Endocrinology 139 137-147.

Usui, M., Yamazaki, T., Kominami, S., and Tsutsui, K. (1995). Avian neurosteroids. II. Localization of a cytochrome P450scc-like substance in the quail brain. Brain Res. 678 , 10-20.

Wang, T., Xie, K., and Lu, B. (1995). Neurotrophins promote maturation of developing neuromuscular synapses. J. Neurosci. 15 4796-4805.

Webb, P., Lopez, G. N., Uht, R. M., and Kushner, P. J. (1995). Tamoxifen activation of the estrogen receptor/AP1 pathway: potential origin for the cell-specific estrogen-like effects of antiestrogens. Mol. Endocrinol. 9, 443-456.

Woolley, C. S., Gould, E., Frankfurt, M., and McEwen, B. S. (1990). Naturally occurring fluctuation in dendritic spine density on adult hippocampal pyramidal neurons. J. Neurosci. 10, 4035-4039.

Woolley, C. S., and McEwen, B. S. (1994). Estradiol regulates hippocampal dendritic spine density via an $N$-methyl-D-aspartate receptordependent mechanism. J. Neurosci. $14,7680-7687$

Conflict of Interest Statement: The authors declare that the research was conducted in the absence of any commercial or financial relationships that could be construed as a potential conflict of interest.

Received: 14 May 2011; accepted: 08 October 2011; published online: 28 October 2011

Citation: Tsutsui K, Ukena K, Sakamoto H, Okuyama S-I and Haraguchi S (2011) Biosynthesis, mode of action, and functional significance of neurosteroids in the Purkinje cell. Front. Endocrin. 2:61. doi 10.3389/fendo.2011.00061

This article was submitted to Frontiers in Neuroendocrine Science, a specialty of Frontiers in Endocrinology.

Copyright (C) 2011 Tsutsui, Ukena, Sakamoto, Okuyama and Haraguchi. This is an open-access article subject to a non-exclusive license between the authors and Frontiers Media SA, which permits use, distribution and reproduction in other forums, provided the original authors and source are credited and other Frontiers conditions are complied with. 